\title{
EVICTION THREATS AND INVESTMENT INCENTIVES
}

\author{
by \\ Abhijit Banerjee \\ Massachusetts Insitute of Technology \\ and \\ Maitreesh Ghatak \\ London School of Economics and Political Science
}

Contents:

Abstract

1. Introduction

2. The Model

3. A Benchmark: The Contractible Investment Case

4. The Non-Contractible Investment Case

4.1 No Commitment

4.2 Full Commitment

4.3 Equilibrium with No Commitment Threats

4.4 Equilibrium with Eviction Threats

5. Welfare

4.5 Extension: Stochastic Eviction Threats

6. Conclusion

7. Appendix

References

Discussion Paper

No. DEDPS/39

June 2003
The Suntory Centre

Suntory and Toyota International Centres for

Economics and Related Disciplines

London School of Economics and Political Science

Houghton Street

London WC2A $2 \mathrm{AE}$

Tel.: 020-7955 6674

We thank Debraj Ray for helpful discussions at an early stage. We also thank Oriana Bandiera, Garance Genicot, and Alexander Karaivanov for useful comments, and Campe Goodman for research assistance. The first draft of the paper was written while both authors were visiting the Indian Institute of Management, Calcutta in the summer of 2001. We thank the Institute for its hospitality. The usual disclaimer applies. 


\section{Abstract}

We show that the effect of eviction threats on unobservable investment effort can be positive. We demonstrate this apparently counter-intuitive result in a model of tenancy where investment by a tenant in the current period raises the chances of doing well in the next period, and therefore retaining the job in the period after next period. If the tenant earns rents, the landlord can partly substitute eviction threats for the crop share as an incentive device. This makes it more attractive for him to elicit investment effort. However, there is a direct negative effect of eviction threats on the tenant's discount factor. We find conditions under which the former effect dominates and eviction threats can increase investment incentives.

Keywords: Sharecropping tenancy; eviction threats; investment incentives.

JEL Nos: D23, D82, O12, Q15.

(C) The authors. All rights reserved. Short sections of text, not to exceed two paragraphs, may be quoted without explicit permission provided that full credit, including (c) notice, is given to the source.

Contact address:

Dr Maitreesh Ghatak, STICERD, London School of Economics and Political Science, Houghton Street, London WC2A 2AE, UK. Email: m.ghatak@lse.ac.uk 


\section{Introduction}

One of the least controversial propositions in economics is that well-defined and secure property rights are important for encouraging investment. ${ }^{1}$ In the context of agricultural tenancy it is widely believed that tenants who have secure tenure will tend to invest more in the land, which seems to be a straightforward corollary of this proposition. $^{2}$ In fact, most tenancy laws have security of tenure as one of their main components (see Appu, 1975 and Hossain, 1982).

Yet, if one takes the point of view of optimal contracting, it is not clear why the landlord would choose to offer insecure tenure if it is bad for investment incentives. Indeed, there is considerable evidence showing that the landlord-tenant relationship is typically a complex long-term informal contract with eviction threats often explicitly used as an incentive device. ${ }^{3}$ Moreover, if insecure tenure takes the form of long term contracts with explicit performance-contingent firing threats, is it necessarily true that they are always bad for investment incentives?

In this paper we address these questions by analyzing a simple dynamic model of tenancy where the tenant chooses an unobservable action that raises the probability of high output in the next period. We will call this action investment effort as distinct from current effort, the latter being an unobservable action that raises the probability of high output in the current period. ${ }^{4}$ We assume that the tenant is risk neutral but there is limited liability. So other than the fact that effort in our model affects output in the next period as opposed to the current period, the framework is very similar to models of sharecropping with limited liability. ${ }^{5}$ Because of limited liability, the tenant must be given a minimum income level each period. Since output can be high or low the landlord faces a trade off between rent extraction and incentive provision. A fixed rent contract which is independent of realized output is good for incentives but because of limited liability the rent that the landlord can charge in this manner

\footnotetext{
${ }^{1}$ See North (1990) for a persuasive statement of this view. Besley (1995) provides a formal analysis of how improved property rights in land provides better investment incentives, and finds evidence for this using micro-level data from Ghana.

${ }^{2}$ This, for example, is the shared view of D. Gale Johnson (1950) and Gunnar Myrdal (1968), two economists with very different views on the effect of sharecropping on incentives to provide effort.

${ }^{3}$ Banerjee, Gertler and Ghatak (2002) report evidence from a survey of 48 villages in West Bengal in 1995. They found that eighty percent of the tenants reported that landlords in their village had used eviction threats and thirty percent reported that they or their fathers were actually threatened. The reasons cited for the use of eviction threats include both low production (in forty percent of the cases) and disputes with the landlord (in fifty-five percent of cases).

${ }^{4}$ Examples of such investments are experimentation with new techniques, care and maintenance of the land, or use of manure the effect of which lasts more than one period. In contrast examples of investments which are observable are installing irrigation equipment, building soil partitions, and planting trees.

${ }^{5}$ See, for example, Shetty (1988), Dutta, Ray and Sengupta (1989), Mookherjee (1997), Ray and Singh (2001), and Banerjee, Gertler and Ghatak (2002).
} 
would typically be low. A contract that charges a higher rent from the tenant when output is high (a share-cropping contract is one example) will be better from the point of view of extracting rents from the tenant, but it will come at the cost of some efficiency, as the tenant will supply a lower level of investment effort.

Given that the tenant typically earns some rents in such environments, the landlord can use eviction threats as an additional incentive device as in models with current effort (see Dutta, Ray, and Sengupta, 1989, and Banerjee, Gertler and Ghatak, 2002). However, since the result of investment is realized with a one period lag, if the tenant is evicted with some probability during this period, he is going to enjoy only a fraction of the benefits from this investment in expected terms. Other things being the same, this would cause the tenant to supply a lower level of investment effort for the same crop share and this is precisely the reason why security of tenure is thought to be good for investment. But there is another, potentially positive, effect of eviction threats on investment that is not well recognized in the literature. Investment in period $t$ raises the chances of doing well in period $t+1$ and hence retaining the job and continuing to earn the rents enjoyed by an incumbent tenant in period $t+2$, just like tomorrow's current effort. The prospect of losing these rents if he is fired, would, all else being the same, cause the tenant to supply the same level of investment effort for a lower crop share in period $t$.

Our premise is that the landlord recognizes both these effects of eviction when he chooses the contract he offers the tenant and moreover that he has enough commitment power that he can, if needed, promise the tenant full security of tenure (or any other probability of eviction) even in the absence of a law. Our first result shows that it is indeed possible that there is more investment when the landlord is allowed to make use of the option of using eviction as a threat. Our second result then shows that in this particular environment, allowing eviction threats does not always increase investment (since the landlord sometimes chooses not to use them) but it never leads to less investment. This is not obvious, since it could be that the landlord chooses to use the extra leeway provided to him by making eviction possible to extract more rents from the tenant at the cost of lowering investment. The reason why this does not happen is because eviction threats are most effective at high levels of investment. When the level of investment effort is high, the tenant is more likely to keep the job and enjoy the fruits of his investment, and also, the discounted value of expected rents in the relationship increases.

Our paper is related to the large theoretical literature on agricultural tenancy (see Singh, 1989 for a review of this literature). The main focus of this literature has been the optimal choice of the contractual form under various types of informational imperfections and transactions costs, and the productivity implications of these optimal contractual choices. In contrast, our paper focuses on two aspects of the tenancy relationship that have received relatively less attention. First, we focus on the dynamic problem of trying to elicit non-observable inputs whose effects are realized with a lag 
(i.e., investment effort as opposed to current effort). Second, we analyze the role of eviction threats as a possible contractual instrument in this environment.

Several papers have dealt with the question of "technology choice" (e.g., the decision to adopt high-yield variety seeds) as opposed to the supply of effort within the context of tenancy.

Braverman and Stiglitz (1986) consider a situation where a landlord is deciding whether to adopt a new technology and address the question if tenancy can be inimical to adoption of new technology. They show, building on an argument originally due to Bhaduri (1973), that even though the technology would have been adopted under the first-best, and is itself contractible, it may not be adopted under the secondbest. If there is moral hazard in the effort supply decision of the tenant, adopting a new technology could raise agency costs and therefore hurt the private profits of the landlord.

Several other papers (Basu, 1992, Sengupta, 1997, and Ghatak and Pandey, 2000) consider an environment where it is the tenant who makes the technology choice, and furthermore this choice is not observable to the landlord. In the presence of limited liability the tenant will have an incentive to choose risky technologies since he is protected against downside risk, which is borne solely by the landlord. Hence a contract that reduces the tenant's marginal return from high outputs, such as a sharecropping contract, will have the advantage of discouraging risk-taking but it will also reduce the incentive to supply effort. While adoption of technology can be interpreted as a form of investment, these models have no dynamic element that separates the time when the costs are incurred and the time when the benefits are realized, and this element is crucial to our argument.

Existing models of tenancy that involve eviction threats as an incentive device to elicit current effort either leave out unobservable investment (e.g., Dutta, Ray, and Sengupta, 1989) or argue that there is a trade-off between the role of eviction in encouraging more current effort by the tenant and the possibility that it may discourage investment effort (e.g., Bardhan, 1984, and Banerjee, Gertler and Ghatak, 2002). Both Bardhan (1984) and Banerjee, Gertler and Ghatak (2002) use two period models and therefore do not capture the effect emphasized in this paper.

Two papers that deal with the problem of eliciting investment effort in a dynamic framework and in that sense are most closely related to our paper are by Ray (2002) and Bose (1993).

Ray (2002) deals with contractible investment in a dynamic model. He considers the problem that the tenant might over-exploit the land to maximize current profits, or might under-supply productivity enhancing investments in land having a shorter time-horizon than the landlord. He shows that the first-best can be achieved by a suitable share-contract which by dampening incentives to maximize current profits addresses the first-problem, and a suitable cost-sharing rule which can address the second problem. Our paper deals with non-contractible investment, and also the role 
of eviction threats which the above mentioned paper does not consider.

Bose (1993) deals with non-contractible investment in a dynamic model. The utility function of the tenant is assumed to be concave in consumption and in order to induce him to supply unobservable investment inputs, the landlord can try to influence his rate of time preference. One way of doing this is to make the tenant's payoff in the investment stage large, which by reducing his marginal utility of current consumption relative to future consumption, will increase investment incentives. The problem is, the tenant will have an incentive to quit the relationship. To the extent long-term credit contracts can be better enforced than long-term tenancy contracts, the landlord might achieve the same result by offering loans at lower than the market rate to the tenant. The tenant's consumption will decline over time to the subsistence level, but as he has an outstanding debt at each point of time, he cannot quit. In our paper the utility function of the tenant is linear in consumption (although there is a limited liability constraint) and so the kind of strategies considered in this paper cannot be applied. Instead, as the tenant earns rents, eviction threats can be used as an alternative incentive device. This is in clear contrast to the above-mentioned paper where the tenant would like to quit but cannot because of his debt obligations to the landlord.

The plan of the paper is as follows. Section 2 describes the model; section 3 briefly describes the first-best (full information and full commitment) allocation as a benchmark; section 4 presents our analysis of the model and reports the main results; the welfare implications are discussed in section 5 , and in section 6 we conclude with a brief discussion of the implications of our analysis for tenancy reform. Some technical proofs are presented in section 7 , the appendix.

\section{The Model}

There is a plot of farm land owned by an infinitely lived landlord who cannot cultivate it himself. In each period he employs exactly one tenant to crop the land. There is a large population of identical infinitely lived tenants who are all willing to work for the landlord as long as he pays them their outside option (or, reservation payoff) in that period, which we normalize to 0 . We assume that the landlord can replace one tenant with another without any cost and as a result firing threats are credible on the part of the landlord. The landlord and the tenants share the same discount factor $\delta<1$.

Output on the farm takes two values, 1 and 0 . To focus on the main question of interest, we assume that the probability of high output depends only on investment effort supplied in the previous period. Formally, the probability of high output in period $t$ is $\tilde{p}\left(k_{t-1}\right)=p+k_{t-1}$ where $k_{t-1}$ denotes the amount of investment effort supplied in period $t-1$ and $p \in\left(\frac{1}{2}, 1\right)$. We assume that $k_{t-1}$ can take three values, $0, x$ and $2 x$ where $x>0$. We will refer to these effort levels as zero, low and high. Let 
the cost of supplying investment effort at the level $k_{t-1}$ be denoted by the function $c\left(k_{t-1}\right)$. We assume $c(0)=0, c(x)=c>0$ and $c(2 x)=\tau c$. We also assume that $\tau \geq 2$, which implies that the cost function is (weakly) convex in the investment effort levels. To ensure that the probability of high output is less than 1, we assume

$$
p+2 x<1 \text {. }
$$

Notice that this assumption puts an upper bound on the value of the parameter $x$, namely $x<\frac{1-p}{2}$.

The effect of investment is assumed to last for just one period and then disappear. Adding persistence would add technical complications without any change in the basic intuition. Even if the tenant does not supply any investment effort, he has to supply some contractible labor inputs for production to take place and in this case, the probability of high output is $\tilde{p}=p$. To minimize notation we set the cost of supplying this contractible labor input to 0 .

Tenants have no wealth, and there is a limited liability constraint which requires that a tenant's payoff in any state of the world has to be non-negative. If the limited liability constraint does not bind the first-best outcome can be achieved given the assumption of risk neutrality. For example, if the tenant is sufficiently wealthy and the landlord can commit to a sequence of fixed rent contracts, this can be achieved. Alternatively, in this case the landlord can sell off the plot of land to the tenant. ${ }^{6}$

Consistent with the assumption that there are many potential tenants and one landlord, we will focus on the equilibrium which maximizes the landlord's per-period profits. In this game the landlord has no reason to discriminate among those who are not working for him in the current period. Therefore if and when he decides to get a new tenant, he can simply choose randomly from among those who are not working for him currently (here we make use of assumption that there are many potential tenants; otherwise the landlord would only randomize among those who have never worked for him).

\section{A Benchmark: The Contractible Investment Case}

Suppose that investment effort is observable, and also that the landlord can commit to make a payment to the tenant conditional on it being supplied. In this case the low effort level will be preferred to the zero effort level if and only if

$$
\delta(p+x)-c \geq \delta p
$$

or

$$
c \leq \delta x .
$$

\footnotetext{
${ }^{6}$ Even if the tenant is not wealthy, if sufficiently strong non-monetary punishments for failure are possible, then the first-best can be attained.
} 
Similarly, the high effort level will be preferred to the low effort level if and only if:

$$
\delta(p+2 x)-\tau c \geq \delta(p+x)-c
$$

or,

$$
(\tau-1) c \leq \delta x .
$$

Since by assumption $\tau \geq 2$, the second condition implies the first condition. We assume that the high effort level would be elicited when investment effort is contractible:

$$
(\tau-1) \frac{c}{\delta x} \leq 1 .
$$

(Assumption 1)

This assumption simply says that the marginal cost of the high investment level is not greater than the discounted value of its expected marginal product.

Given that the landlord has all the bargaining power, he can capture the entire benefit from the investment by simply paying the tenant the cost of investment. Therefore, if investment effort is contractible and the landlord can commit to a contract that stipulates a transfer to the tenant conditional on investment, Assumption 1 is a necessary and sufficient condition for the high investment level to be undertaken.

\section{The Non-contractible Investment Case}

Consider now the case where investment effort is subject to moral hazard. To be able to elicit any investment effort, the landlord has to offer some incentives to the tenant, i.e., reward the tenant more when output is high than when it is low. Since output takes two values, the single-period contract maps these output realizations into monetary rewards for the tenant as well as a probability of continuing in the job for one more period. In principle the dynamic contract does not have to be a repetition of the single-period contract. In practice, allowing for this possibility complicates the calculations without changing anything substantial. We therefore limit ourselves to the case where the landlord offers a stationary contract, so that each period looks the same along the equilibrium path.

\subsection{No Commitment}

We first look at the case where the landlord cannot commit to the next period's contract. We do not model why the landlord cannot commit. It could be that the effective discount factor is too low to take advantage of supergame strategies either because the parties are impatient or because there are exogenous frictions that lead to breaking up of existing relationships with high probability. It could also be due to the fact that external enforcement devices are absent. Finally, the landlord and all his potential tenants could be playing the "bad" equilibrium of the supergame for some 
historical reasons. The only possible equilibrium in this setting is to repeat the oneshot equilibrium and since investment is sunk one period ahead of time, there is no reason to pay the tenant more than his outside option in any one-shot equilibrium. Since the tenant knows that he will just get his outside option whether or not he chooses a positive level of investment, he will choose not to invest at all. Therefore, if investment effort is non-contractible and if the landlord cannot commit to the next period's contract today, then the tenant will not supply any investment effort.

\subsection{Full Commitment}

Next, let us consider the case where the landlord can commit to a stationary sequence of contracts which specify both the tenant's rewards based on whether output is high or low, (which we denote by $h$ and $l$ ) and whether or not he is going be fired if output is low. Limited liability implies the following constraints: $h \geq 0$ and $l \geq 0$. It is straightforward to show that the landlord would never fire the tenant with a positive probability when output is high. In addition, to simplify matters, we assume that firing the tenant when his output is low is a 0 or 1 decision. In section 4.5 we discuss briefly the possibility that the landlord can fire the tenant with some probability.

Once again we will not model how the landlord is able to commit to this contract. One possibility is a supergame equilibrium where, after the first time the landlord deviates, the landlord and his future tenants always play the one-shot equilibrium. Another possibility is the existence of some external enforcement mechanism.

The timeline is as follows. At the beginning of period $t$, the investment sunk by the tenant in period $t-1$ is given. Given this, the tenant supplies contractible effort (which matters for output today) and the level of investment, which determines output in the next period. After this, today's output is known and the terms of the contract (namely, how much income the tenant receives and whether he is retained for the next period) are carried out.

Since the tenant is risk neutral, there is no potential gain from rewarding him when output is low, but there is a cost in terms of reducing the incentive to succeed. Also, since reservation payoff of the tenant is zero the landlord would never want to pay him a positive amount when he fails. Therefore $l=0$. Since the high level of output is 1 and $l=0$, we can refer to $h$ as the crop-share of the tenant, and $1-h$ as the crop share of the landlord. ${ }^{7}$

${ }^{7} \mathrm{~A}$ clarification is in order about what we mean by fixed-rent or share-cropping contracts in this particular environment. We could have alternatively talked in terms of linear contracts, where the tenant's income is $s Y-r$, with $s$ denoting the crop-share of the tenant and $r$, a fixed-rent component (which can, in principle, be negative in which case it is a fixed-wage component) and $Y \in\{0,1\}$ denoting output. Then in terms of current notation $s=h-l$ and $r=-l$. As output takes only two values in this model, these two sets of contracts are equivalent. A fixed rent contract involves $h-l=1$ but as the tenant has no wealth $l=0$ and so this contract yields zero-profit to the landlord. That is why one would always observe "share" contracts in this set up. 
The following simple result will be useful in the subsequent analysis. Let the increase in the tenant's payoff when he succeeds compared to when he fails be $R$. Let $V$ be the tenant's lifetime expected payoff in the relationship. If the landlord does not use eviction threats as an incentive device then $R=(h+\delta V)-(l+\delta V)=h$. If eviction threats are used such that the tenant is fired with certainty if output is low but retained with certainty if output is high, then $R=(h+\delta V)-l=h+\delta V$.

Lemma 1 For a given reward from success to the tenant, $R$, if he prefers $k=2 x$ to $k=x$, then he prefers $k=x$ to $k=0$.

Proof: See the appendix.

The result follows directly from the fact that the tenant's expected income $\tilde{p} R$ is linear in the level of investment effort, and the cost of effort is (weakly) convex. As a result, if the high effort level is preferred to the low effort level, the latter must be preferred to the zero effort level since in both cases the marginal benefit is the same but the marginal cost is higher in the former case.

\subsection{Equilibrium with No Eviction Threats}

Consider first the equilibrium with no eviction. It can be interpreted as a setting where the landlord chooses to sign a formal contract granting permanent tenure to the tenant, or one where he is unable to fire him at will because of tenancy laws. The landlord simply commits to a stationary sequence of success wages, $h$.

The success wage at which the tenant prefers to choose the high level to the low level of investment effort is:

$$
\delta(p+2 x) h-\tau c \geq \delta(p+x) h-c
$$

or

$$
h \geq(\tau-1) \frac{c}{\delta x} \equiv \bar{h}^{N} .
$$

Similarly, the success wage at which the tenant prefers to choose the low level to the zero level of investment effort is:

$$
\delta(p+x) h-c \geq \delta p h
$$

or,

$$
h \geq \frac{c}{\delta x} \equiv \underline{h}^{N} .
$$

As $\tau \geq 2, \bar{h}^{N} \geq \underline{h}^{N}$ with strict inequality holding for $\tau>2$. Also, by Assumption 1 , the share of output that the landlord needs to offer to the tenant to elicit the high effort level, $(\tau-1) \frac{c}{\delta x}$, does not exceed 1 . 
Since giving the tenant a share of output is a costly method to give incentives from the landlord's point of view, it may not always be optimal for him to elicit the high investment effort in the second-best world with moral hazard in investment effort. The landlord will choose to elicit the high investment effort level if and only if:

$$
\delta(p+2 x)\left(1-\bar{h}^{N}\right) \geq \delta(p+x)\left(1-\underline{h}^{N}\right) .
$$

The intuition behind this condition is simple. It is the same as that of a monopsonist deciding whether to offer a higher per unit price for an input he buys. This will naturally cut into his profits per unit of the input but it might be worthwhile doing it if the increased supply of the input allows production to expand sufficiently so as to raise the level of profits. In this case, a higher input price corresponds to a higher crop-share of the tenant (with the extra rent being $(\tau-2) \frac{c}{\delta x}$ ), and an increased supply of the input that allows output to expand corresponds to a move from the low to the high effort level.

It is straightforward to check that the above condition is equivalent to $\frac{a(\tau-1)}{a(\tau-1)+(\tau-2)} \geq$ $(\tau-1) \frac{c}{\delta x}$ where $a \equiv \frac{x}{p+x}<1$. Since the left hand side of this condition is less than 1 (strictly so for $\tau>2$ ) it is possible that a positive level of investment effort will not be elicited in the presence of moral hazard even though it is efficient to do so in the absence of moral hazard. In the presence of moral hazard the tenant has to be given some rents to supply investment effort. If the tenant was wealthy, making him the full residual claimant using a fixed rent contract would solve the problem. But given that the tenant has no money, the only way the landlord can give him incentives is by giving him a share of output, which is costly from the landlord's point of view. Therefore, the efficient investment effort level need not always be elicited. ${ }^{8}$

If a positive level of investment effort is elicited, the tenant earns rents in the optimal one-shot contract (recall that his outside option is 0 ) and so he will want to avoid losing his position. The landlord could then use the threat of evicting him if output fails to give him the incentive to invest at a lower cost. ${ }^{9}$ Can this sometimes be optimal even though firing threats have a direct negative effect on the tenant's effective discount factor? We examine this possibility next.

\subsection{Equilibrium with Eviction Threats}

Let $V\left(k_{t-1}\right)$ denote the lifetime expected utility of an incumbent tenant at the beginning of period $t$. Then

\footnotetext{
${ }^{8}$ The reasoning here is the same as Mookherjee (1997) and Banerjee, Gertler and Ghatak (2002) to explain why current effort will be undersupplied in a model with risk neutrality and limited liability.

${ }^{9}$ The landlord can commit to using this threat because he is indifferent between continuing with this tenant and getting a new one.
} 


$$
V\left(k_{t-1}\right)=\max _{k_{t}}\left[\left(p+k_{t-1}\right) h-c\left(k_{t}\right)+\delta\left(p+k_{t-1}\right) V\left(k_{t}\right)\right] .
$$

That is, given his investment decision in the last period, the tenant succeeds with probability $p+k_{t-1}$ and receives a direct payment of $h$. In addition, he enjoys the discounted expected future payoff from staying on in the relationship for one more period. From this one has to subtract the cost of current investment.

Suppose the tenant chooses the high investment level. Because we focus on stationary equilibria we can set $V\left(k_{t-1}\right)=V\left(k_{t}\right)$ and solve from (3) the tenant's stationary lifetime expected utility as:

$$
\bar{V}=\frac{(p+2 x) h-\tau c}{1-\delta(p+2 x)} .
$$

The success wage of the tenant such that he is indifferent between choosing the high and the low effort level on the equilibrium path is ${ }^{10}$ :

$$
\delta(p+2 x)^{2}(h+\delta \bar{V})-\tau c \geq \delta(p+2 x)(p+x)(h+\delta \bar{V})-c
$$

By Lemma 1, for this value of the success wage the tenant would strictly prefer the high effort level to the zero effort level.

Substituting the value of $\bar{V}$ given by (4) into (5) to get

$$
h \geq \frac{1-\delta(p+2 x)}{p+2 x}(\tau-1) \frac{c}{\delta x}+\delta \tau c \equiv \bar{h}^{E} .
$$

Given the limited liability constraint, we must make sure that $h>0$. This is true, as $\tau>1, \delta \leq 1$ and $p+2 x<1$.

Similarly, we can find out the minimum success wage the landlord needs to offer to elicit the low investment level. Now

$$
\underline{V}=\frac{(p+x) h-c}{1-\delta(p+x)}
$$

The success wage of the tenant such that he is indifferent between choosing the low effort level and the zero effort level on the equilibrium path is:

$$
\delta(p+x)^{2}(h+\delta \underline{V})-c \geq \delta(p+x) p(h+\delta \underline{V})
$$

or,

$$
h \geq \frac{1-\delta(p+x)}{p+x} \frac{c}{\delta x}+\delta c \equiv \underline{h}^{E} .
$$

\footnotetext{
${ }^{10}$ We are using the one-period deviation rule here: the tenant considers the implication of deviating from the high to the low effort level in the current period only.
} 
Now we are ready to analyze the main questions of interest. Is it possible for it to be cheaper for the landlord to elicit investment effort when eviction threats are used? If this is so, does allowing eviction threats necessarily lead to a higher level of investment effort?

A direct comparison of $\underline{h}^{N}$ and $\underline{h}^{E}$ implies that $\underline{h}^{E} \leq \underline{h}^{N}$ if and only if

$$
\frac{1}{p+x} \leq 1+\delta(1-\delta x)
$$

We are now ready to prove:

\section{Proposition 1 :}

(i) For any $x \in\left(0, \frac{1-p}{2}\right)$ there exists $\underline{\delta}<1$ such that for $\delta \geq \underline{\delta}, \underline{h}^{E} \leq \underline{h}^{N}$. Conversely, there exists $\delta_{0}<1$ such that for any $\delta \in\left(\delta_{0}, 1\right)$ there exists $\underline{x}<\frac{1-p}{2}$ such that for $x \geq \underline{x}, \underline{h}^{E} \leq \underline{h}^{N}$.

(ii) If $\underline{h}^{E} \leq \underline{h}^{N}$, then $\bar{h}^{E} \leq \bar{h}^{N}$.

\section{Proof: See the appendix.}

The first part of the above proposition says that if the tenant is patient enough ( $\delta$ is high enough) or the marginal product of investment effort $(x)$ is high enough, then the optimal contract for eliciting the low level of effort involves eviction threats. The intuition for this result is as follows. If one compares the incentive compatibility constraint for eliciting a given level of investment effort when eviction threats are used with the one where eviction threats are not used (e.g., compare (1) with (5) or (2) with (7)), there are two main differences. First, when eviction threats are used the tenant is not guaranteed to keep the job which reduces the tenant's effective discount factor (i.e., the true discount factor $\delta$ times the probability of remaining in the next period, $\tilde{p}$ ). Other things being the same, this reduces the incentive to invest for the same crop share. Second, success brings a higher marginal reward to the tenant compared to failure - he not only gets his success wage, but also the discounted value of expected future rents in the relationship. If eviction threats are not used, the tenant enjoys these rents irrespective of whether output is high or low. This second effect increases the incentive to invest for the same crop share. Making $x$ higher limits the size of the first effect. Also, for the same crop share, the higher is $\delta$ and $x$, the greater is the discounted value of expected future rents and this increases the size of the second effect.

The second part of the proposition says that if it is cheaper to elicit the low level of investment effort using eviction threats, then it must be cheaper to elicit the high level of investment effort using eviction threats. This result has a simple intuition. A higher level of investment effort raises the probability of the tenant keeping the job. 
Also, it raises the effective discount factor of the tenant and therefore, the discounted value of expected future rents. Therefore, by the above argument it makes eviction threats more effective as a source of incentives.

Proposition 1 showed that if the tenant is patient enough or the marginal product of investment effort is high enough then allowing eviction threats reduces the cost of eliciting investment effort on the part of the landlord. This raises the question: can giving the landlord the additional contractual option to evict the tenant hurt efficiency? It is well known that in models of moral hazard with limited liability, curtailing the set of contracts the landlord can offer to the tenant may increase efficiency (see Mookherjee, 1987, and Banerjee, Gertler and Ghatak, 2002). Intuitively, in our model, while it should be true that the total cost of eliciting investment effort goes down for every level of investment effort when eviction threats are allowed, in principle, the marginal cost of eliciting a higher investment effort level could go up compared to the regime where eviction threats are not allowed. However, the following result shows that this is not the case:

Proposition 2: Starting with a situation where eviction threats are not allowed, if they are allowed the landlord will never choose to elicit a lower level of investment.

Proof: See the appendix.

If it is costlier to elicit investment effort using eviction threats than without, then the landlord will not be using them and so allowing eviction threats will not affect the equilibrium level of investment effort. Suppose it is cheaper to elicit investment effort using eviction threats. For both eviction and non-eviction regimes, eliciting the higher investment effort is costlier for the landlord because of the increasing marginal cost of effort of the tenant. But as we showed in part two of Proposition 1, eviction threats work better the higher the level of investment as the tenant's effective discount factor is higher. This factor tends to reduce the marginal cost of eliciting the high effort level to the landlord under the eviction regime relative to the no-eviction regime. This, and the fact that the high output is more likely when the high investment effort is chosen, implies that the increase in the landlord's profit from choosing the high investment effort is higher under the eviction regime.

We conclude this section with a discussion of how these results relate to the literature on the effect of eviction threats on current effort incentives, and the literature on the relationship between the labor (or land) market and the credit market, and contracts that interlink tenancy and credit transactions.

Suppose the benefit of the effort put in by the tenant is realized in the current period, and not with a lag. This is the case of current effort, and it is well known that eviction threats will increase current effort in an environment like this (see Dutta, Ray, 
Sengupta, 1989 and Banerjee, Gertler and Ghatak, 2002). This is indeed confirmed in our current framework. The analysis is very similar, but now there is no direct disincentive effect of eviction threats on the tenant's effective discount factor. As a result, the only effect of eviction threats is to allow the landlord to offer a lower success wage to elicit the same effort level because now the marginal reward to the tenant from success is higher as he gets both the success wage, and the discounted value of expected future rents. Moreover, the higher is the effort level the greater is the discounted value of expected future rents for the same level of one-period rents, and therefore the marginal cost of eliciting a higher current effort level is lower with eviction threats than without. As a result eviction threats will always be used if available, and allowing them can never reduce the equilibrium level of effort. In contrast, we showed that in the case of investment effort eviction threats will be used only when the tenant is patient enough or the marginal product of investment is high enough. This discussion confirms the intuition offered by some papers in the context of two-period models (e.g., Bardhan, 1984, and Banerjee, Gertler and Ghatak, 2002) that it is easier to elicit current effort than investment effort using eviction threats. In both cases eviction threats enable the landlord to reduce the crop share and makes it more attractive for him to elicit the relevant type of effort. But in the case of investment effort there is a direct negative effect of eviction threats on the tenant's effective discount factor, which is absent in the case of current effort.

Finally, a few words on how the results would be affected by the presence of a credit market, and whether interlinking tenancy with credit transactions can improve efficiency. To begin with, it might appear that if there is a perfectly competitive credit market in which the tenant can participate, perhaps he can buy out the land from the landlord and that will eliminate all agency costs. As has been pointed out by Mookherjee (1997), lenders will face the same moral hazard problem relative to the tenant (unless they have access to better information than the landlord) and so in this sense, credit markets must be inherently imperfect in this environment. Still, the presence of a credit market would influence the outside option of the tenant in his relationship with the landlord, and these kind of inter-market interactions raise many interesting issues that are beyond scope of this paper. ${ }^{11}$ As tenants are risk neutral in our framework, credit transactions with the landlord do not generate any gains from trade in the form of risk-sharing or consumption-smoothing. However, the landlord might want to induce the tenant to save (and these can be implemented through some form of interlinked credit-market transactions), and then use these savings to relax the limited liability constraint in future periods. ${ }^{12}$

\footnotetext{
${ }^{11}$ Genicot (2002) and Ghatak, Morelli, and Sjöström (2002) are some recent papers that have explored interactions between the labor and the credit market.

${ }^{12}$ For a treatment of repeated moral hazard problems that explores issues relating to availability of credit to the agent see Chiappori et al (1994). Mookherjee and Ray (2002) have shown that in the kind of environment we are looking at, where the principals (here, landlords) have a lot of
} 


\subsection{Extension: Stochastic Eviction Threats}

So far we restricted attention to non-stochastic eviction threats, i.e., if eviction threats are used at all, the tenant is retained with certainty when output is high and evicted with certainty when output is low. However, it seems intuitive that the landlord may prefer not to always fire the tenant when output is low. This will raise the tenant's effective discount factor and enable the landlord to reduce the success wage needed to elicit a desired level of investment effort. Our basic point that eviction threats can actually enhance investment incentives would be strengthened if we were to go in this direction. Here we discuss briefly the possibility of using stochastic eviction threats.

Let $\phi \in[0,1]$ be the probability that the landlord retains the tenant conditional on output being high and let $\psi \in[0,1]$ be the corresponding probability when output is low. Then the probability that the tenant retains his job is

$$
\phi\left(p+k_{t-1}\right)+\psi\left(1-p-k_{t-1}\right)=(\phi-\psi)\left(p+k_{t-1}\right)+\psi .
$$

Therefore we have

$$
V\left(k_{t-1}\right)=\max _{k_{t}}\left[\left(p+k_{t-1}\right) h-c\left(k_{t}\right)+\delta\left\{(\phi-\psi)\left(p+k_{t-1}\right)+\psi\right\} V\left(k_{t}\right)\right] .
$$

Consider the case where the low investment effort is elicited. The same argument applies for the case where the high investment effort is elicited. Let $\lambda \equiv(\phi-\psi)(p+$ $x)+\psi$ be the probability that the tenant is retained. Then

$$
\underline{V}=\frac{(p+x) h-c}{1-\delta \lambda}
$$

The success wage of the tenant such that he is indifferent between choosing the low effort level and the zero effort level on the equilibrium path is given by the following incentive-compatibility constraint:

$$
\delta \lambda\{(p+x) h+\lambda \delta \underline{V}\}-c \geq \delta \lambda[p h+\{(\phi-\psi) p+\psi\} \delta \underline{V}] .
$$

This simplifies to

$$
h \geq \frac{c}{x} \frac{1}{1-\delta \psi}\left[\frac{1-\delta \lambda}{\delta \lambda}+\delta x(\phi-\psi)\right] \equiv \frac{c}{x} g(\phi, \psi) .
$$

Note that if we set $\phi=1$ and $\psi=0$ then the right-hand side equals $\underline{h}^{E}$. Similarly, for $\phi=1$ and $\psi=1$ the right-hand side equals $\underline{h}^{N}$. Earlier we restricted ourselves to comparing $\underline{h}^{E}$ with $\underline{h}^{N}$ only. Now we would like to see if by choosing some other

bargaining power, agents (here, tenants) will not have any incentive to save on their own since the efficiency gains arising out of these will be appropriated by landlords. However, unlike the current paper they focus on short-period contracts. 
values of $\phi$ and $\psi$ can the landlord achieve a lower value of $h$ needed to elicit the low investment effort level.

Straightforward algebra shows that $g(\phi, \psi)$ is decreasing and convex in $\phi$ for $\phi \in$ $[0,1]$ and for any given value of $\psi \in[0,1] .{ }^{13}$ Therefore, the landlord will in fact choose $\phi=1$ as was assumed earlier. Henceforth, we will assume $\phi=1$. Now we proceed to provide the following "local" characterization of the choice of $\psi$.

Suppose $\underline{h}^{E} \leq \underline{h}^{N}$, which from our earlier analysis is true if and only if

$$
\frac{1}{p+x} \leq 1+\delta(1-\delta x)
$$

In this case, starting with $\psi=0$ would the landlord prefer choosing some positive value of $\psi$ ? A sufficient condition for the optimal value of $\psi$ to be positive is for $\frac{\partial g(\phi, \psi)}{\partial \psi}$ evaluated at $\psi=0$ and $\phi=1$ to be negative. This condition is, upon simplification,

$$
\frac{1}{p+x}>(1+\delta)-\delta^{2}(1-\delta) x(p+x)
$$

Notice that $(1+\delta)-\delta^{2}(1-\delta) x(p+x)>(1+\delta)-\delta^{2}(1-\delta) x$ as $p+x \in(0,1)$. But as $1+\delta(1-\delta x)<1+\delta-\delta^{2}(1-\delta) x$, this condition and the condition $\frac{1}{p+x} \leq 1+\delta(1-\delta x)$ cannot hold simultaneously. Therefore, in the case where $\underline{h}^{E} \leq \underline{h}^{N}$, evaluated at $\psi=0$, small increases in $\psi$ are not worthwhile to the landlord.

Consider now the case where $\underline{h}^{E}>\underline{h}^{N}$, which from our earlier analysis is the case if and only if

$$
\frac{1}{p+x}>1+\delta(1-\delta x)
$$

In this case, would the landlord prefer choosing some value of $\psi$ that is lower than 1? A sufficient condition for this is $\frac{\partial g(\phi, \psi)}{\partial \psi}<0$ evaluated at $\psi=1$ and $\phi=1$. This condition is, upon simplification, $\frac{1}{p+x} \geq \frac{1}{1-\delta(1-\delta x)}$. Notice that $\frac{1}{1-\delta(1-\delta x)}>1+\delta(1-\delta x)$ as $\delta(1-\delta x) \in(0,1)$. Therefore this condition is consistent with $\frac{1}{p+x}>1+\delta(1-\delta x)$. Therefore, in the case where $\underline{h}^{E}>\underline{h}^{N}$ (i.e., non-eviction will be chosen in the case of non-stochastic eviction threats) evaluated at $\psi=1$ (i.e., no eviction) a small reduction in $\psi$ is worthwhile to the landlord under some parameter conditions.

\section{Welfare}

The landlord is always (weakly) better off when eviction threats are permitted - this introduces the possibility of reducing the amount of money he has to pay to the tenant to elicit the same level of investment. The welfare implication for the tenant

${ }^{13}$ In particular, the first-derivative with respect to $\phi$ is $-\frac{1}{(1-\delta \psi) \delta \lambda^{2}}\left[p+x\left(1-\delta^{2} \lambda^{2}\right)\right]$ which is negative, and the second derivative is $\frac{2}{\delta(1-\delta \psi)} \frac{1}{\lambda^{3}}(p+x)^{2}$, which is positive. 
is not clear. When the level of investment effort is $k \in\{0, x, 2 x\}$, the tenant's lifetime expected utility is:

$$
V^{N}(k)=\frac{(p+k) h^{N}(k)-c(k)}{1-\delta}
$$

when eviction threats are not used, where $h^{N}(0)=0, h^{N}(x)=\underline{h}^{N}$, and $h^{N}(2 x)=\bar{h}^{N}$. If eviction threats are used, the tenant's lifetime expected utility is:

$$
V^{E}(k)=\frac{(p+k) h^{E}(k)-c(k)}{1-\delta(p+k)}
$$

where $h^{E}(0)=0, h^{E}(x)=\underline{h}^{E}$, and $h^{E}(2 x)=\bar{h}^{E}$.

If eviction threats are used, we know from Proposition 2 that the high investment effort level would be elicited. There are three cases to consider depending on which level of investment effort is elicited without eviction threats.

First, suppose that the high level of investment is chosen when eviction threats are not allowed. Since the tenant's crop share is lower under eviction threats, the tenant has a lower per-period payoff. Furthermore, his effective discount factor is lower with eviction threats, so his lifetime expected utility is lower as well. Therefore, the tenant is strictly worse off if eviction threats are used in this case.

Second, suppose that the low level of investment is elicited when eviction threats are not allowed. Now the tenant has a lower crop share and a lower effective discount factor when eviction threat are used, but a higher probability of success compared to when eviction threats are not used. As a result we cannot say in general whether he is better off or worse off. However, if the discount factor of the tenant is high enough the lifetime expected utility when eviction threats are not used is strictly higher because as $\delta \rightarrow 1, V^{N}(x)$ becomes arbitrarily large whereas $V^{E}(2 x)$ tends to some finite limit.

Third, and finally, if the zero effort level is chosen when eviction threats are not allowed, then the tenant's lifetime expected utility is zero, and so he is better off when eviction threats are used.

\section{Conclusion}

In this paper we have analyzed a very simple model to demonstrate the possibility that eviction threats can increase unobservable investment effort. This suggests the conventional (and eminently intuitive) argument that security of tenure is good for investment should be applied with caution.

More importantly, the analysis implies that policy makers need to be conscious of how policy interventions interact with existing informal rights. The initial contract faced by the tenant is not necessarily the equilibrium of the one-shot game between the landlord and the tenant, i.e., they may be in a repeated relationship. Informal 
rights are defined by the properties of this long-term relationship. In the admittedly very specific environment considered here, banning the right to evict never helps. If the landlord cannot commit to future streams of payment (i.e., the informal rights of the tenant are weak), then banning eviction has no effect. With or without the option to use eviction threats, there will be no investment since the tenant knows that once the investment is sunk, the landlord will extract all the rents. In the full commitment case, where the landlord can commit to future contracts (i.e., the informal rights of the tenant are strong) our analysis shows that if eviction threats are in fact used in equilibrium, then banning them always reduces investment and efficiency.

These very definite conclusions do rely on the rather specific structure we impose. For example, in a model where output depends on both current effort and investment effort and greater investment increases the marginal product of current effort in the future, the rents received by the tenant may go up as a result of the investment, which would give him a reason to invest as long as he has security of tenure. If, in this environment, the landlord cannot voluntarily commit not to fire the tenant (for example, because once the investment is sunk, he can sell the land) it may be in both of their interests to restrict eviction by law. ${ }^{14}$

However, the broader argument that when informal rights of tenants are strong, policy interventions may make matters worse does not depend on the specific structure of the current model. In the literature on the implementation of tenancy laws (see for example, Appu, 1975) one often hears about "anticipatory eviction" of tenants by the landlord. Apprehensive of the fact that their tenants could take advantage of newly passed tenancy laws, landlords sometimes pre-emptively evict them. In a world where landlords are good at committing to long-term implicit contracts but tenants are not, tenancy laws therefore create the potential for "opportunism" by the tenant from the point of view of the landlord, and the resulting outcome may hurt both parties. Whether this bad outcome actually occurs or not depends on how tight the laws are (e.g., whether they have loopholes such as those that allow the landlord to withdraw leased out land for "personal cultivation"), and the implementation process.

It is important to stress that our results do not imply that laissez faire is always the best option even within the world of our model, and even when the informal rights of the tenant are strong. The source of inefficiency in this model is the following: given that the tenant has no wealth, the only way the landlord can extract some surplus from him is to take a share of output, but this diminishes investment incentives. Therefore, a policy that not only restricts eviction but also puts a ceiling on the share of output that the landlord can claim as rent, will help promote investment. ${ }^{15}$ Many successful tenancy reform programs (e.g., Taiwan, the Philippines, and the Indian states of Kerala and West Bengal) indeed do combine these elements.

${ }^{14}$ See Banerjee, Gertler and Ghatak (2002) for a two-period model that illustrates this point.

${ }^{15}$ Obviously giving the land to the tenant will solve the entire problem. 


\section{$7 \quad$ Appendix}

Proof of Lemma 1: If

$$
(p+2 x) R-\tau c \geq(p+x) R-c
$$

then $x R \geq(\tau-1) c$. As $\tau \geq 2$, we get $x R \geq c$ which can be rewritten as:

$$
(p+x) R-c \geq p R
$$

\section{Proof of Proposition 1}

(i) The right hand side of (9) is a strictly increasing and concave function of $\delta$ for $\delta \in[0,1]$. For $\delta=0$, the left hand side exceeds the right hand side. But for $\delta=1$, the right hand side exceeds the left hand side. This is because the relevant inequality $\frac{1}{p+x}<2-x$ is equivalent to $(2 p-1)+x\{2-(p+x)\}>0$ which holds as $p>\frac{1}{2}, x>0$ and $p+x<1$ by assumption. Therefore by continuity there exists $\underline{\delta} \in(0,1)$ defined by the equation

$$
\frac{1}{p+x}=1+\underline{\delta}\{1-\underline{\delta} x\}
$$

such that for $\delta \geq \underline{\delta}$ the condition (9) is satisfied. Clearly, $\underline{\delta}$ depends on $x$. Given that the above equation is a quadratic in $\underline{\delta}$ we can solve explicitly for the two roots:

$$
\underline{\delta}=\frac{1 \pm \sqrt{1-4 x\left(\frac{1}{p+x}-1\right)}}{2 x} .
$$

By assumption $p+2 x<1$ and $p>\frac{1}{2}$ which implies $x<\frac{1}{4}$. Also, $\frac{1}{p+x}$ cannot exceed 2 (as $x>0$ and $p>\frac{1}{2}$ by assumption) and so $\frac{1}{p+x}-1<1$. These two observations imply that $1>4 x\left(\frac{1}{p+x}-1\right)$ and so both roots are real. Moreover, as $2 x<1$, only the smaller root is relevant because the larger root is greater than 1 . The lower root is obviously positive. The condition for it being less than 1 , after some simplification, is $x+\frac{1}{p+x}<2$. By a previous argument, $x<\frac{1}{4}$ and by assumption, $p>\frac{1}{2}$. Given this, it is straightforward to check that for all $x \in\left(0, \frac{1}{4}\right)$ the left-hand side of this inequality is less than the right-hand side. Therefore, for any given $x$ there is a $\underline{\delta}(x) \in(0,1)$ such that $\delta \geq \underline{\delta}(x)$ the condition (9) is satisfied. This proves the first part of Proposition 1 , part (i).

To prove the second part of Proposition 1, part (i) we first establish that $\underline{\delta}(x)$ is decreasing in $x$. Totally differentiating both sides with respect to $x$, we get

$$
\{\underline{\delta}(x)\}^{2}-\frac{1}{(p+x)^{2}}=\{1-2 x \underline{\delta}(x)\} \frac{d \underline{\delta}(x)}{d x} .
$$


As $\{\underline{\delta}(x)\}^{2}<1<\frac{1}{(p+x)^{2}}$ and $1-2 x \underline{\delta}(x)>0\left(\right.$ as $\underline{\delta}(x)<1$, and $\left.x<1-p<\frac{1}{2}\right)$, $\underline{\delta}(x)$ is decreasing in $x$. Let $\underline{\delta}\left(\frac{1-p}{2}\right) \equiv \delta_{0}$. Recall that by the proof of the first part of Proposition 1 part (i), $\delta \geq \delta_{0}$ is equivalent to the condition that the right hand side of (9) is greater than the left hand side for $x=\frac{1-p}{2}$. Now consider a particular value of $\delta$, say $\delta_{1}$. By our earlier argument, there is a unique value of $x$, say $x_{1}<$ $\frac{1-p}{2}$ such that $\delta_{1}=\underline{\delta}\left(x_{1}\right)$ and for $x=x_{1}$ and $\delta=\delta_{1}$ the equation (10) is satisfied. Since $x_{1}<\frac{1-p}{2}, \delta_{1}>\delta_{0}$ as $\underline{\delta}(x)$ is decreasing. We would like to show that for higher values of $x$, holding $\delta=\delta_{1}$, the inequality (9) will continue to be satisfied. Notice that the left hand side of (9) is a monotonically decreasing and convex function of $x$ while the right hand side is a decreasing linear function of $x$. However, for all $x \in\left(0, \frac{1-p}{2}\right)$ the slope of the left hand side with respect to $x$, namely, $-\frac{1}{(p+x)^{2}}$, is greater in absolute value than the slope of the right hand side with respect to $x$, namely, $-\delta^{2}$, as $\delta<1<\frac{1}{p+x}$. Therefore holding $\delta=\delta_{1}$, the inequality (9) will be satisfied for $x \geq x_{1}$. From this we can conclude that for any given $\delta \in\left(\delta_{0}, 1\right)$ there exists a critical value of $x, \underline{x} \in\left(0, \frac{1-p}{2}\right)$ such that the right hand side exceeds the left hand side for all $x \geq \underline{x}$. This proves the second part of Proposition 1, part (i).

(ii) Recall that the condition $\underline{h}^{N}-\underline{h}^{E} \geq 0$ is equivalent to the inequality (9) being satisfied. From (5) and (7), $\bar{h}^{E}-\underline{h}^{E}=c\left[\delta-\frac{1}{\delta(p+x)(p+2 x)}\right]+(\tau-2)\left[\frac{c}{\delta x}\left(\frac{1}{p+2 x}-\delta\right)+\delta c\right]$ and from (1) and (2), $\bar{h}^{N}-\underline{h}^{N}=(\tau-2) \frac{c}{\delta x}>0$. Therefore, $\left(\bar{h}^{E}-\underline{h}^{E}\right)-\left(\bar{h}^{N}-\underline{h}^{N}\right)=$ $c\left[\delta-\frac{1}{\delta(p+x)(p+2 x)}\right]+(\tau-2) \frac{c}{\delta x}\left[\frac{1}{p+2 x}-\{1+\delta(1-\delta x)\}\right]$. Notice that the first term is negative as $\delta \leq 1<\frac{1}{\delta(p+x)(p+2 x)}$. Also, the second term is negative since we assume (9) is satisfied and $\frac{1}{p+2 x}<\frac{1}{p+x}$. Therefore, $\bar{h}^{E}-\underline{h}^{E} \leq \bar{h}^{N}-\underline{h}^{N}$, which can be rearranged as $\underline{h}^{N}-\underline{h}^{E} \leq \bar{h}^{N}-\bar{h}^{E}$. Therefore, if $\underline{h}^{N}-\underline{h}^{E} \geq 0$, then $\bar{h}^{N}-\bar{h}^{E} \geq 0$.

Proof of Proposition 2: A direct comparison of $\bar{h}^{N}$ and $\bar{h}^{E}$ implies that $\bar{h}^{E} \leq \bar{h}^{N}$ if and only if

$$
\frac{1}{p+2 x} \leq 1+\delta\left(1-\frac{\tau}{\tau-1} \delta x\right)
$$

From the proof of part (ii) of Proposition 1, if (9) is satisfied (which is equivalent to $\underline{h}^{E}-\underline{h}^{N} \leq 0$ ), then (11) is satisfied (which is equivalent to $\bar{h}^{E}-\bar{h}^{N} \leq 0$ ). Therefore, we need to consider three cases.

First, if (11) is not satisfied then it is costlier to elicit both the low and the high levels of investment effort using eviction threats and so they will not be used in equilibrium. In this case allowing eviction threats will not change anything.

Second, suppose (11) is satisfied but (9) is not. Clearly, the only change that could possibly take place if eviction threats are allowed is that the high investment effort is chosen. 
Third, and finally, suppose (9) is satisfied so that it is cheaper to elicit both the low and the high investment effort levels using eviction threats. The landlord's marginal gain from choosing the higher investment effort when eviction threats are permitted is

$$
\delta\left\{\left(1-\bar{h}^{E}\right)(p+2 x)-\left(1-\underline{h}^{E}\right)(p+x)\right\} .
$$

Without eviction threats, it is

$$
\delta\left\{\left(1-\bar{h}^{N}\right)(p+2 x)-\left(1-\underline{h}^{N}\right)(p+x)\right\} .
$$

We show that the former is higher when (9) is satisfied. Rearranging terms, the relevant inequality is $\left(\bar{h}^{N}-\bar{h}^{E}\right)(p+2 x) \geq\left(\underline{h}^{N}-\underline{h}^{E}\right)(p+x)$. Since we show above $\left(\bar{h}^{E}-\underline{h}^{E}\right)-\left(\bar{h}^{N}-\underline{h}^{N}\right) \leq 0$, or, $\left(\bar{h}^{N}-\bar{h}^{E}\right) \geq\left(\underline{h}^{N}-\underline{h}^{E}\right)$, this inequality holds if (9) is satisfied.

\section{References}

[1] Appu, P. S. (1975): "Tenancy reform in India". Economic and Political Weekly, Special Number, August.

[2] Banerjee, A.V., P. J. Gertler, and M. Ghatak (2002): "Empowerment and Efficiency: Tenancy Reform in West Bengal", Journal of Political Economy, 110 (2), 239-280.

[3] Bardhan. P. (1984): Land, Labor, and Rural Poverty: Essays in Development Economics. New York: Columbia University Press.

[4] Basu, K. (1992): "Limited Liability and the Existence of Share Tenancy", Journal of Development Economics, 38, 203-220.

[5] Besley, T. (1995) : "Property rights and investment incentives: theory and evidence from Ghana", Journal of Political Economy, 103 (5), 903-937.

[6] Bhaduri, A. (1973): "A Study in Agricultural Backwardness under SemiFeudalism", Economic Journal, 83 (329), 120-137.

[7] Bose, G. (1993): "Interlinked Contracts and Moral Hazard in Investment", Journal of Development Economics, 41, 247-273.

[8] Braverman, A. and J. Stiglitz (1986): "Landlords, Tenants and Technological Innovations", Journal of Development Economics, 23, 313-332. 
[9] Chiappori, P.-A., I. Macho, P. Rey and B. Salanie (1994): "Repeated Moral Hazard: The Role of Memory, Commitment, and the Access to Credit Markets", European Economic Review, 38, 1527-1553.

[10] Dutta B., D. Ray and K. Sengupta (1989): "Contracts with eviction in infinitely repeated principal-agent relationships" in P. Bardhan (ed.) The Economic Theory of Agrarian Institutions, Clarendon Press, Oxford.

[11] Genicot, G. (2002): "Bonded Labor and Serfdom: A Paradox of Voluntary Choice", Journal of Development Economics, 67, 101-127.

[12] Ghatak, M. and P. Pandey (2000): "Contract Choice in Agriculture with Joint Moral Hazard in Effort and Risk", Journal of Development Economics, 63, 303326.

[13] Ghatak, M., M. Morelli, and T. Sjöström (2002): "Credit Rationing, Wealth Inequality, and Allocation of Talent", Discussion Paper TE/2002/441, STICERD, London School of Economics.

[14] Hossain, M. (1982) : "Agrarian Reform in South Asia - A Review of Recent Experiences in Selected Countries", in Rural Poverty and Agrarian Reform, (ed.s) Steve Jones, P.C. Joshi, and Miguel Murmis, Allied Publishers: New Delhi.

[15] Johnson, D. G. (1950): "Resource allocation under share contracts", Journal of Political Economy, 58(2), 111-123.

[16] Mookherjee, D. (1997): "Informational rents and property rights in land", in J. Roemer (ed.) Property Rights, Incentives, and Welfare, London : Macmillan Press.

[17] Myrdal, G. (1968): Asian Drama - An Inquiry Into the Poverty of Nations, Vol. II, New York: Pantheon.

[18] North, D. (1990) : Institutions, Institutional Change and Economic Performance. Cambridge University Press, Cambridge.

[19] Ray, T. (2002): "Sharecropping, Land Exploitation, and Land Improving Investments", Working Paper, Department of Economics, Hong Kong University of Science and Technology.

[20] Ray, T. and N. Singh (2001): "Limited Liability, Contractual Choice, and the Tenancy Ladder", Journal of Development Economics, 66, 289-303.

[21] Sengupta, K. (1997): "Limited Liability, Moral Hazard, and Share Tenancy", Journal of Development Economics, 52, 393-407. 
[22] Shetty, S. (1988): "Limited Liability, Moral Hazard, and Share Tenancy", Journal of Development Economics, 29, 1-22.

[23] Singh, N. (1989): "Theories of Sharecropping" in P. Bardhan (ed.) The Economic Theory of Agrarian Institutions, Clarendon Press, Oxford. 